\title{
Tuberização de Dois Cultivares de Batata sob Aplicação de SULFONILURÉIAS ${ }^{1}$
}

\author{
Effect of Sulfonylurea Herbicides on Tuberization of Two Potato Cultivars
}

NOVO, M.C.S.S. ${ }^{2}$ e MIRANDA FILHO, H.S. ${ }^{3}$

\begin{abstract}
RESUMO - A resposta de plantas de batata à simulação de contaminação de tanques de pulverizadores com sulfoniluréias foi avaliada em experimento em vasos, em Águas da Prata-SP, 2004. O objetivo deste trabalho foi avaliar o efeito de subdoses de metsulfuron-methyl, nicosulfuron e sulfometuron-methyl em dois cultivares de batata quanto à produção e qualidade dos tubérculos. Metsulfuron-methyl, nicosulfuron e sulfometuron-methyl foram aplicados em pós-emergência em plantas de batata dos cultivares Atlantic e Lady Rosetta. As doses aplicadas foram correspondentes às recomendadas para solo argiloso $\mathrm{x}, 0,1 \mathrm{x}, 0,01 \mathrm{x}, 0,001 \mathrm{x}$, $0,0001 x, 0,00001 x$ e 0 , em que $x$ foi considerada a dose recomendada de cada herbicida (g ha-1): para metsulfuron-methyl a 3, nicosulfuron a 60 e sulfometuron-methyl a 15. Por ocasião da colheita foram avaliados a massa fresca de raiz, o número e as massas frescas de tubérculos normais, anormais e da produção total. Nenhuma das doses provocou morte nas plantas de batata. As sulfoniluréias afetaram o desenvolvimento dos tubérculos e causaram anomalias, mas elas também foram dependentes do produto e das doses aplicadas. As perdas na produção de 'Atlantic' foram maiores que em 'Lady Rosetta' quando as plantas foram tratadas com metsulfuron-methyl. A produção de tubérculos de 'Lady Rosetta' foi mais sensivel que a de 'Atlantic', quando tratadas com nicosulfuron e sulfometuron-methyl.
\end{abstract}

Palavras-chave: Solanum tuberosum, metsulfuron-methyl, nicosulfuron, sulfometuron-methyl.

\begin{abstract}
Potato response to simulated tank contamination of three sulfonylurea herbicides was evaluated in a pot study in Águas da Prata, São Paulo, Brazil. The purpose of the trial was to study the effect of subdoses of the herbicides metsulfuron-methyl, nicosulfuron and sulfometuron-methyl on yield and tuber quality of two potato cultivars. Metsulfuron-methyl, nicosulfuron and sulfometuron-methyl were applied in post-emergence on 'Atlantic' and 'Lady Rosetta' cultivars at rates corresponding to 0, 0.00001, 0.0001, 0.001, 0.01, 0.1 and 1 times the recommended rate. At harvest, root fresh weight, number and fresh weight of normal and malformed tubers and total yield of tubers were determined. None of the rates applied killed the potato plants. Sulfonylurea application affected tuber development causing anomalies but these also varied with products and rates. 'Atlantic' yield losses were greater than 'Lady Rosetta's yield losses when metsulfuron-methyl was applied. 'Lady Rosetta' tuber yield was more sensitive than that of Atlantic to nicosulfuron and sulfometuron-methyl.
\end{abstract}

Keywords: Solanum tuberosum, metsulfuron-methyl, nicosulfuron, sulfometuron-methyl.

Recebido para publicação em 16.8.2005 e na forma revisada em 24.2.2006.

2 Pesquisadora Científica do Centro de Ecofisiologia e Biofísica do Instituto Agronômico (IAC), Caixa Postal 28, 13001-970 Campinas-SP, <mcdesalvo@ @otmail.com>; ${ }^{3}$ Pesquisador Científico do Centro de Horticultura do IAC, Campinas-SP, $<$ hilario@iac.sp.gov.br>. 


\section{INTRODUÇÃO}

A batata (Solanum tuberosum) destaca-se como um dos quatro alimentos mais consumidos no mundo, sendo superada apenas pelo trigo, arroz e milho (Miranda Filho et al., 2003). Por ser uma cultura muito sensível a doenças e pragas, o emprego de produtos químicos na defesa fitossanitária é prática considerada obrigatória. Entre as muitas tecnologias de proteção de plantas passíveis de serem empregadas nessa cultura, o uso da pulverização aérea tem se tornado uma alternativa cada vez mais interessante, pela sua maior flexibilidade de aplicação em relação a condições de clima e de solo, bem como pelo aumento de produtividade a ela associado devido à redução absoluta de danos às plantas quando das operações de defesa fitossanitária. Grande importância tem-se dado à escolha do produto a ser aplicado, menosprezando-se as condições do ambiente por ocasião da aplicação, o equipamento, a qualidade da água, a limpeza dos pulverizadores antes e depois da aplicação e o nível de conhecimento dos aplicadores (Ruedell et al., 2004).

Em 2004, no Estado de São Paulo, nos municípios de Casa Branca e Aguaí, foram observadas anormalidades na tuberização da batata em duas áreas de plantio. Em Casa Branca, logo após a primeira pulverização verificou-se a ocorrência de sintomas de intoxicação na parte aérea das plantas, que posteriormente deixaram de ser observados. Esse campo havia sido tratado com equipamento que fora utilizado em cultura de triticale onde foi aplicado metsulfuron-methyl. Contudo, quando do início de tuberização, notou-se que todos os tubérculos de todas as plantas apresentavam numerosas rachaduras, semelhantes às descritas por Thornton \& Eberlein (2001) como relacionadas à contaminação com sulfoniluréias. O mesmo foi constatado no campo de Aguaí. Posteriormente, verificou-se que os dois campos haviam recebido pulverização aérea no mesmo dia e pelo mesmo avião. Este tinha tido como sua tarefa imediatamente anterior a aplicação do regulador vegetal sulfometuron-methyl, utilizado como maturador de cana-de-açúcar. Esse produto, nos Estados Unidos, é utilizado como herbicida em florestas, com dose muito maior que a empregada no Brasil como regulador vegetal. Entretanto, nos Estados Unidos não é admitido que um tanque que tenha recebido esse produto possa ser utilizado para outra finalidade agrícola (Vencill, 2002). No Brasil, a lavagem do equipamento é recomendada, com o emprego de soluções amoniacais (Rodrigues \& Almeida, 2005).

Na região de Casa Branca e Aguaí tem-se usado a rotação batata-milho com o emprego de nicosulfuron; utiliza-se também pulverização aérea com metsulfuron-methyl em região canavieira próxima a esses campos. O uso de produtos do grupo das sulfoniluréias tem sido crescente nas agriculturas paulista, brasileira e mundial. Segundo Oliveira Júnior (2001), os herbicidas inibidores da ALS foram responsáveis por cerca de $17 \%$ do mercado mundial de herbicidas em 1994, mais do que qualquer outro grupo isoladamente. Os produtos desse grupo apresentam meia-vida de 30 a 120 dias nos solos (Trezzi \& Vidal, 2001), podendo, eventualmente, permanecer na área de um ciclo para outro e induzir, em cultivares suscetíveis, problemas de fitotoxicidade em concentrações de até partes por trilhão (Thornton \& Eberlein, 2001).

A possível contaminação dos tanques dos equipamentos de pulverização com sulfoniluréias parece ser capaz de causar problemas sérios para a bataticultura. O objetivo deste trabalho foi avaliar o efeito de subdoses de metsulfuron-methyl, nicosulfuron e sulfometuron-methyl, simulando contaminação com resíduos desses produtos no tanque de pulverização, em dois cultivares de batata, quanto à produção e à qualidade dos tubérculos.

\section{MATERIAL E MÉTODOS}

O experimento foi instalado em vasos com capacidade para $5 \mathrm{~L}$, preenchidos com terra, em Águas da Prata-SP, 2004. A terra empregada no experimento foi peneirada, corrigida e adubada de acordo com Miranda Filho (1996). Os resultados das análises químicas de amostras coletadas na área do experimento foram: matéria orgânica: 5,6 $\mathrm{g} \mathrm{dm}^{-3} ; \mathrm{pH}$ em $\mathrm{CaCl}_{2}: 5,6 ; \mathrm{P}: 58,9 \mathrm{mg}_{\mathrm{c}} \mathrm{dm}^{-3} ; \mathrm{K}: 6,5 \mathrm{mmol}_{\mathrm{c}} \mathrm{dm}^{-3}$; Ca: $44 \mathrm{mmol}_{c} \mathrm{dm}^{-3}$; $\mathrm{Mg}$ : $10 \mathrm{mmol}_{c} \mathrm{dm}^{-3} ; \mathrm{H}+\mathrm{Al}$ : $20 \mathrm{mmol}_{\mathrm{cm}} \mathrm{dm}^{-3}$ CTC: $81 \mathrm{mmol}_{\mathrm{cm}}^{-3}$; V: 75,2\%; S: 42,6 $\mathrm{mg} \mathrm{dm}^{-3}$; Na: $26 \mathrm{mg} \mathrm{dm}^{-3}$; Fe: 
$14 \mathrm{mg} \mathrm{dm}^{-3} ; \mathrm{Mn}: 21,4 \mathrm{mg} \mathrm{dm}^{-3}$; $\mathrm{Cu}: 4,7 \mathrm{mg} \mathrm{dm}^{-3}$; Zn: 39,0 mg dm${ }^{-3}$; e B: 0,4 mg dm ${ }^{-3}$.

O delineamento experimental foi inteiramente casualisado, em um arranjo fatorial completo, $2 \times 3 \times 7$, em que se avaliaram dois cultivares (Atlantic e Lady Rosetta), três produtos (metsulfuron-methyl, nicosulfuron e sulfometuron-methyl) e sete doses, com quatro repetições, sendo cada repetição representada por uma única planta. Os tubérculos-semente, em estádio fisiológico de fim de dormência (Miranda Filho et al, 2003), foram plantados em 2/11/2004 na profundidade de 0,15 m. As aplicações dos produtos foram feitas em pós-emergência quando as plantas estavam com 30 dias, diferentes em altura, segundo o hábito varietal, mas em igualdade de condições fisiológicas. A aplicação foi feita com pulverizador costal de precisão pressurizado por $\mathrm{CO}_{2}$, equipado com barra com quatro bicos do tipo leque $80.015 \mathrm{E}$, espaçados de $0,50 \mathrm{~m} \mathrm{e}$ mantidos a $0,50 \mathrm{~m}$ das plantas. A pressão de trabalho foi de $2,4 \mathrm{kgf} \mathrm{cm}^{-2}$, o que possibilitou o consumo médio de calda correspondente a $365 \mathrm{~L} \mathrm{ha}^{-1}$. As doses aplicadas correspondentes às recomendadas para solo argiloso $\mathrm{x}$, $0,1 x, 0,01 x, 0,001 x, 0,0001 x, 0,00001 x$ e 0 , para metsulfuron-methyl, nicosulfuron e sulfometuron-methyl, foram, respectivamente: $3 ; 0,3 ; 0,03 ; 0,003 ; 0,0003 ; 0,00003$ e $0 \mathrm{~g} \mathrm{ha}^{-1}$; $60 ; 6 ; 0,6 ; 0,06 ; 0,006 ; 0,0006$ e $0 \mathrm{~g} \mathrm{ha}^{-1}$; e 15; 1,$5 ; 0,15 ; 0,015 ; 0,0015 ; 0,00015$ e $0 \mathrm{~g} \mathrm{ha}^{-1}$.

Em 'Lady Rosetta', nos tratamentos com metsulfuron-methyl e sulfometuron-methyl, a colheita dos tubérculos foi feita 35 dias após a aplicação dos produtos. A colheita dos tubérculos de 'Atlantic' tratados com os três produtos e de 'Lady Rosetta' com nicosulfuron foi realizada 42 dias após a aplicação. Por ocasião da colheita foram realizadas as seguintes observações: número de hastes, número e massa fresca de tubérculos normais, anormais e total e massa fresca de raiz.

Os dados foram submetidos à análise de variância, com emprego do teste $F(D<0,05)$. Os dados de número de hastes e de tubérculos foram transformados em $\sqrt{x \square 1}$ para análise estatística. Quando as diferenças foram significativas, compararam-se as médias dos tratamentos dos cultivares e dos produtos pelo teste de Duncan $(D<0,05)$. O efeito de doses dos produtos e suas interações foi caracterizado por equações de ajuste que melhor representaram o comportamento da variação, sendo consideradas as equações em que os coeficientes de determinação foram iguais ou superiores a $60,0 \%$ e com significado biológico.

\section{RESULTADOS E DISCUSSÃO}

\section{Efeito na produção de tubérculos}

Todos os produtos causaram anomalias na tuberização. A mais evidente é a rachadura dos tubérculos, em muitos casos semelhantes às de origem fisiológica (Turkensteen \& Mulder, 2005); todavia, com o aumento das doses, outros tipos de anormalidades podem surgir, conforme as descritas por Eberlein \& Guttieri (1994), com rachaduras múltiplas e profundas, dobramento dos tubérculos, tubérculos em caracol, numerosos tubérculos secundários ligados a um único tubérculo, tuberização em cadeia e outros. Todos esses sintomas foram agrupados em "tubérculos anormais".

Metsulfuron-methyl: com aplicação de metsulfuron-methyl, o cultivar Lady Rosetta produziu mais hastes e maior número de tubérculos normais e de total de tubérculos que 'Atlantic' (Tabela 1). Portanto, 'Atlantic' apresentou maior sensibilidade ao metsulfuron-methyl no desenvolvimento dos tubérculos. A massa fresca de tubérculos anormais e de total de tubérculos foi menor em 'Lady Rosetta'. Não houve diferença entre cultivares tratados com metsulfuron-methyl quanto a número e massa fresca de tubérculos anormais e massa fresca de raiz. Fleck \& Vidal (1993) observaram que em plantas de girassol tratadas com chlorimuron-ethyl houve menos efeito no sistema radicular que na parte aérea. Para esses autores há três explicações possíveis para o fato: a) menor atividade da ALS no sistema radicular; b) ocorrência de enzimas menos sensíveis a esses compostos nas raízes; e c) maior detoxificação das moléculas do produto no sistema radicular.

Nicosulfuron: não houve diferença entre cultivares no número de hastes e no número de tubérculos anormais produzidos com a aplicação de nicosulfuron (Tabela 1). Em relação ao número de tubérculos normais e total de tubérculos, verificou-se que, com 
nicosulfuron, 'Lady Rosetta' foi superior a 'Atlantic'. Quando as plantas de batata foram tratadas com esse produto, verificou-se que as massas frescas de raiz, de tubérculos anormais e de total de tubérculos foram maiores no cultivar Atlantic. Não houve diferença entre cultivares para massa fresca de tubérculos normais.

Sulfometuron methyl: não houve diferença entre cultivares quando as plantas de batata foram tratadas com sulfometuronmethyl para número de hastes e de tubérculos anormais e para massas frescas de raiz e de tubérculos normais (Tabela 1). A película de 'Atlantic' foi claramente afetada pelas doses mais elevadas de sulfometuron-methyl, apresentando um reticulado (Russet) setorial. Em 'Lady Rosetta', o mesmo foi observado apenas em tubérculos muito pequenos; este cultivar apresentou maior número de tubérculos normais e de total de tubérculos que 'Atlantic'. Entretanto, este apresentou maior massa fresca de tubérculos anormais e de total de tubérculos.

\section{Efeito de doses}

Metsulfuron-methyl: embora Eberlein \& Guttieri (1994) tenham relatado que, quando plantas de batata são tratadas com metsulfuron-methyl, pode ocorrer a proliferação de raízes anormais e pequenas em todo o sistema radicular ou em parte deste, esse fato não foi observado no presente experimento. Não houve efeito de doses de metsulfuron-methyl quanto ao número de hastes e massas frescas de raiz e de total de tubérculos (Tabela 2). Foi observado que em plantas tratadas com a dose de $3 \mathrm{~g} \mathrm{ha}^{-1}$ o desenvolvimento do sistema radicular era exuberante. Dexter et al. (1994) observaram que sulfoniluréias afetam o funcionamento do sistema radicular e que as plantas, para sobreviverem, produzem raízes secundárias no hipocótilo. Os números de tubérculos normais, anormais e de total de tubérculos foram exponencialmente afetados pela aplicação de doses crescentes de metsulfuron-methyl. Andres \& Fleck (1994) relataram que, devido à sua rápida translocação e por se acumularem em tecidos meristemáticos, as sulfoniluréias exercem ação sobre a divisão celular de plantas sensiveis. A translocação de moléculas desse grupo de herbicidas até o embrião em desenvolvimento pode torná-lo inviável através de sua ação em alguma via metabólica ou atuando sobre a síntese de aminoácidos, interferindo na divisão celular e impedindo a formação de tubérculos

Tabela 1 - Efeito de metsulfuron-methyl, nicosulfuron e sulfometuron-methyl nos cultivares Atlantic e Lady Rosetta quanto a número de hastes, de tubérculos normais, anormais e total de tubérculos e massas frescas de raiz, tubérculos normais, anormais e total de tubérculos - Águas da Prata-SP, 2004

\begin{tabular}{|l|c|c|c|c|c|c|c|c|}
\hline \multirow{2}{*}{ Cultivar } & \multicolumn{9}{c|}{ Número $^{-1 /}$ por planta } & \multicolumn{5}{c|}{ Massa fresca (g por planta) } \\
\cline { 2 - 9 } & Haste & $\begin{array}{c}\text { Tubérculo } \\
\text { normal }\end{array}$ & $\begin{array}{c}\text { Tubérculo } \\
\text { anormal }\end{array}$ & $\begin{array}{c}\text { Total de } \\
\text { tubérculos }\end{array}$ & Raiz & $\begin{array}{c}\text { Tubérculo } \\
\text { normal }\end{array}$ & $\begin{array}{c}\text { Tubérculo } \\
\text { anormal }\end{array}$ & $\begin{array}{c}\text { Total de } \\
\text { tubérculos }\end{array}$ \\
\hline \multicolumn{8}{|c|}{ Metsulfuron-methyl } \\
\hline Atlantic & $3,1 \mathrm{~b}^{2 /}$ & $4,8 \mathrm{~b}$ & $4,0 \mathrm{a}$ & $8,8 \mathrm{~b}$ & $68,3 \mathrm{a}$ & $236,3 \mathrm{a}$ & $143,2 \mathrm{a}$ & $379,5 \mathrm{a}$ \\
\hline Lady Rosetta & $3,9 \mathrm{a}$ & $12,0 \mathrm{a}$ & $0,3 \mathrm{a}$ & $12,3 \mathrm{a}$ & $58,6 \mathrm{a}$ & $256,6 \mathrm{a}$ & $32,9 \mathrm{~b}$ & $289,5 \mathrm{~b}$ \\
\hline CV (\%) & 13,6 & 39,6 & 33,7 & 18,1 & 29,7 & 37,7 & 29,5 & 19,8 \\
\hline \multicolumn{7}{|c|}{ Nicosulfuron } \\
\hline Atlantic & $3,7 \mathrm{a}$ & $5,2 \mathrm{~b}$ & $2,0 \mathrm{a}$ & $7,2 \mathrm{~b}$ & $56,0 \mathrm{a}$ & $254,5 \mathrm{a}$ & $68,1 \mathrm{a}$ & $322,6 \mathrm{a}$ \\
\hline Lady Rosetta & $3,3 \mathrm{a}$ & $9,7 \mathrm{a}$ & $1,5 \mathrm{a}$ & $11,2 \mathrm{a}$ & $30,8 \mathrm{~b}$ & $242,8 \mathrm{a}$ & $21,7 \mathrm{~b}$ & $264,5 \mathrm{~b}$ \\
\hline CV (\%) & 13,8 & 19,4 & 31,7 & 18,4 & 37,1 & 28,4 & 32,16 & 21,6 \\
\hline \multicolumn{7}{|c|}{ Sulfometuron-methyl } \\
\hline Atlantic & $3,3 \mathrm{a}$ & $3,8 \mathrm{~b}$ & $6,7 \mathrm{a}$ & $10,5 \mathrm{~b}$ & $59,0 \mathrm{a}$ & $203,1 \mathrm{a}$ & $89,7 \mathrm{a}$ & $292,8 \mathrm{a}$ \\
\hline Lady Rosetta & $3,8 \mathrm{a}$ & $8,0 \mathrm{a}$ & $5,7 \mathrm{a}$ & $13,7 \mathrm{a}$ & $56,4 \mathrm{a}$ & $195,5 \mathrm{a}$ & $36,9 \mathrm{~b}$ & $232,4 \mathrm{~b}$ \\
\hline CV (\%) & 14,1 & 18,4 & 33,7 & 23,6 & 34,2 & 31,4 & 27,1 & 22,3 \\
\hline
\end{tabular}

1/ Dados transformados em $\sqrt{x \square 1}$ para análise, mas são apresentados os dados originais. 리 Médias seguidas pela mesma letra, na coluna, não diferem entre si pelo teste de Duncan a $5 \%$ de probabilidade. 
Tabela 2 - Equações de ajuste e os respectivos coeficientes de determinação para efeito de doses de metsulfuron-methyl, nicosulfuron e sulfometuron-methyl quanto a número de hastes, de tubérculos normais, anormais e total de tubérculos e para massa fresca de raiz, de tubérculos normais, anormais e total de tubérculos de batata- Águas da Prata-SP, 2004

\begin{tabular}{|c|c|c|}
\hline Variável analisada & \multicolumn{2}{|c|}{ Equação de ajustes e respectivo coeficiente de determinação (\%) } \\
\hline \multicolumn{3}{|c|}{ Metsulfuron-methyl } \\
\hline Número de hastes ${ }^{1 /}$ & Não-significat & \\
\hline Número de tubérculos normais ${ }^{1 /}$ & $\mathrm{Y}=3,17 \cdot \mathrm{e}^{-0,3 \mathrm{x}}$ & $\mathrm{R}^{2}=62,92 \%$ \\
\hline Número de tubérculos anormais ${ }^{1}$ & $\mathrm{Y}=11,41 \cdot\left(1,09-\mathrm{e}^{-0,13 \mathrm{x}}\right)$ & $\mathrm{R}^{2}=99,95 \%$ \\
\hline Número de total de tubérculos ${ }^{\underline{1}}$ & $\mathrm{Y}=3,20 \cdot 1,10^{\mathrm{x}}$ & $\mathrm{R}^{2}=84,65 \%$ \\
\hline Massa fresca de raiz & \multicolumn{2}{|l|}{ Não-significativo } \\
\hline Massa fresca de tubérculos normais & $Y=282,93-76,63 x$ & $\mathrm{R}^{2}=96,98 \%$ \\
\hline Massa fresca de tubérculos anormais & $Y=52,36+74,83 x$ & $\mathrm{R}^{2}=95,15 \%$ \\
\hline Massa fresca de total de tubérculos & \multicolumn{2}{|c|}{ Não-significativo } \\
\hline \multicolumn{3}{|c|}{ Nicosulfuron } \\
\hline 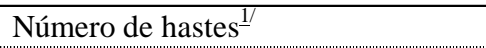 & $Y=2,06+0,00678 x$ & $\mathrm{R}^{2}=85,40 \%$ \\
\hline Número de tubérculos normais ${ }^{1 /}$ & $\mathrm{Y}=3,05-0,0187 \mathrm{x}$ & $\mathrm{R}^{2}=94,67 \%$ \\
\hline Número de tubérculos anormais ${ }^{1 /}$ & $Y=200,08 /\left(1+21,63 \cdot e^{-0,405 x}\right)$ & $\mathrm{R}^{2}=99,58 \%$ \\
\hline Número de total de tubérculos ${ }^{1 /}$ & $Y=3,09+0,00083 x+0,00056 x^{2}$ & $\mathrm{R}^{2}=98,58 \%$ \\
\hline Massa fresca de raiz & \multicolumn{2}{|l|}{ Não-significativo } \\
\hline Massa fresca de tubérculos normais & $Y=299,156 . e^{-0,048 x}$ & $\mathrm{R}^{2}=97,53 \%$ \\
\hline Massa fresca de tubérculos anormais & $\mathrm{Y}=197,32 \cdot\left(1,037-\mathrm{e}^{-0,063 \mathrm{x}}\right)$ & $\mathrm{R}^{2}=99,66 \%$ \\
\hline Massa fresca de total de tubérculos & \multicolumn{2}{|l|}{ Não-significativo } \\
\hline \multicolumn{3}{|c|}{ Sulfometuron-methyl } \\
\hline Número de hastes ${ }^{1 /}$ & $Y=2,16-0,087 x+0,0054 x^{2}$ & $\mathrm{R}^{2}=70,00 \%$ \\
\hline Número de tubérculos normais ${ }^{1 /}$ & $Y=3,21-1,605 x+0,0971 x^{2}$ & $\mathrm{R}^{2}=97,67 \%$ \\
\hline Número de tubérculos anormais ${ }^{1}$ & $Y=1,10+3,691 x-0,222 x^{2}$ & $\mathrm{R}^{2}=99,87 \%$ \\
\hline Número de total de tubérculos ${ }^{\underline{\prime}}$ & $Y=3,16+2,182 x-0,131 x^{2}$ & $\mathrm{R}^{2}=99,65 \%$ \\
\hline Massa fresca de raiz & $\mathrm{Y}=1 /\left(0,0145+0,0055 \mathrm{x}^{0,234}\right)$ & $\mathrm{R}^{2}=83,79 \%$ \\
\hline Massa fresca de tubérculos normais & $Y=286,46-211,89 x+12,853 x^{2}$ & $\mathrm{R}^{2}=97,34 \%$ \\
\hline Massa fresca de tubérculos anormais & $Y=23,21+137,55 x-8,852 x^{2}$ & $\mathrm{R}^{2}=95,10 \%$ \\
\hline Massa fresca de total de tubérculos & $Y=309,67-74,339 x+4,022 x^{2}$ & $\mathrm{R}^{2}=97,55 \%$ \\
\hline
\end{tabular}

1/ Dados transformados em $\sqrt{x \square 1}$ para análise.

íntegros e sem rachaduras. Há ainda a possibilidade de esse produto ser acumulado nos tecidos de reserva do tubérculo para posterior liberação, o que foi observado por Isaacs et al. (1989) em Cassia obtusifolia. A massa fresca de tubérculos normais foi linearmente reduzida com o aumento da dose de metsulfuronmethyl. A massa fresca de tubérculos anormais foi linearmente aumentada em função das doses crescentes desse produto.

Nicosulfuron: houve aumento linear no número de hastes com a aplicação de nicosulfuron, mas o número de tubérculos normais formados foi linearmente reduzido com o aumento da dose aplicada (Tabela 2). Houve incremento exponencial no número de tubérculos anormais com o aumento da dose. Observou-se que a aplicação de nicosulfuron estimulou a formação do número total de tubérculos, sendo verificado acréscimo de mais de $60 \%$ com $60 \mathrm{~g}$ de ingrediente ativo em relação à testemunha. Plantas de batata tratadas com nicosulfuron apresentaram tubérculos em caracol e dobrados, com um lado nitidamente maior que o outro. Não houve efeito de nicosulfuron nas massas frescas de raiz e de total de tubérculos, porém foram observadas raízes sendo emitidas a partir dos tubérculos. Já foi demonstrado que tubérculos de batata podem originar radicelas, mas não há relatos de longas raízes saindo de um tubérculo. A massa fresca de tubérculos normais foi exponencialmente reduzida com o aumento da dose de nicosulfuron, e a de tubérculos anormais foi exponencialmente aumentada. 
Sulfometuron-methyl: houve aumento no número de hastes de tubérculos normais de batata com a redução das doses de sulfometuron-methyl aplicadas de acordo com uma equação do segundo grau (Tabela 2). Houve decréscimo no número de tubérculos anormais e de total de tubérculos com a redução das doses de sulfometuron-methyl, demonstrando que doses mais elevadas aumentam a produção de tubérculos com protuberância. A massa de raiz foi exponencialmente aumentada com a redução da dose. Houve aumento nas massas frescas de tubérculos normais e de total de tubérculos com a redução da dose de sulfometuron-methyl aplicada de acordo com uma equação do segundo grau. A massa fresca de tubérculos anormais foi reduzida com a diminuição da dose aplicada.

Comparação entre herbicidas: não houve diferença entre os três produtos aplicados quanto ao número de hastes emitidas (Tabela 3). Plantas de batata tratadas com metsulfuron-methyl produziram mais tubérculos normais que com sulfometuron-methyl. $\mathrm{O}$ número de tubérculos anormais foi maior nos tratamentos com sulfometuron-methyl, não havendo diferença quando as plantas foram tratadas com metsulfuron-methyl ou nicosulfuron. Considerando o número total de tubérculos produzidos, verificou-se que não houve diferença quando a aplicação foi feita com sulfometuron-methyl ou nicosulfuron, porém foi sempre menor com metsulfuronmethyl.

Verificou-se que nicosulfuron reduziu mais a massa fresca de raiz que os outros dois produtos. Não houve diferença estatística quanto à massa fresca de tubérculos normais quando as plantas foram tratadas com metsulfuron-methyl ou nicosulfuron, mas foi menor com sulfometuron-methyl. A massa fresca de tubérculos anormais foi maior quando as plantas de batata foram tratadas com metsulfuron-methyl e menor com sulfometuron-methyl e nicosulfuron. Considerando o total de tubérculos, verificou-se que, quando tratadas com metsulfuron-methyl, as plantas apresentaram maior massa, sendo esta menor com sulfometuron-methyl. Embora os sintomas induzidos por metsulfuron-methyl nas plantas de Atlantic fossem menos severos que os de sulfometuron-methyl, esse produto também causou anomalias a tubérculos em doses tão baixas quanto $0,0001 x$ e mesmo 0,00001x. Diferentemente dessas doses de nicosulfuron, em que as rachaduras presentes eram, pela freqüência e pelo tipo de sintoma, possivelmente de causa fisiológica, as dos tubérculos de plantas tratadas com metsulfuronmethyl foram devidas ao produto. Ocorreram deformações dos tubérculos provocadas pela dose maior de metsulfuron-methyl, mas estas foram menos severas do que as observadas no tratamento com sulfometuron-methyl. O sistema radicular das plantas tratadas com a dose maior de metsulfuron-methyl também foi exuberante.

Concluiu-se que: nenhuma das doses aplicadas provocou a morte das plantas; as raízes e a parte aérea foram menos afetadas pela aplicação das sulfoniluréias que a tuberização; os três produtos causaram anomalias no desenvolvimento dos tubérculos, sendo sulfometuron-methyl o mais prejudicial e o nicosulfuron o menos; o cultivar Atlantic foi mais sensivel que o 'Lady Rosetta' a metsulfuron-methyl; e 'Lady Rosetta' mostrou

Tabela 3 - Comparação entre os diferentes produtos aplicados quanto a número de hastes, de tubérculos normais, anormais e total de tubérculos e massas frescas de raiz, tubérculos normais, anormais e total de tubérculos- Águas da Prata-SP, 2004

\begin{tabular}{|l|c|c|c|c|c|c|c|c|}
\hline \multirow{2}{*}{ Produto } & \multicolumn{4}{|c|}{ Número $^{1 /}$ por vaso } & \multicolumn{4}{c|}{ Massa fresca (g por vaso) } \\
\cline { 2 - 10 } & Haste & $\begin{array}{c}\text { Tubérculo } \\
\text { normal }\end{array}$ & $\begin{array}{c}\text { Tubérculo } \\
\text { anormal }\end{array}$ & $\begin{array}{c}\text { Total de } \\
\text { tubérculos }\end{array}$ & Raiz & $\begin{array}{c}\text { Tubérculo } \\
\text { normal }\end{array}$ & $\begin{array}{c}\text { Tubérculo } \\
\text { anormal }\end{array}$ & $\begin{array}{c}\text { Total de } \\
\text { tubérculos }\end{array}$ \\
\hline Metsulfuron & $3,5 \mathrm{a}^{\underline{2}}{ }^{\prime}$ & $8,0 \mathrm{a}$ & $1,9 \mathrm{~b}$ & $9,9 \mathrm{~b}$ & $63,4 \mathrm{a}$ & $246,4 \mathrm{a}$ & $88,0 \mathrm{a}$ & $334,4 \mathrm{a}$ \\
\hline Nicosulfuron & $3,6 \mathrm{a}$ & $7,3 \mathrm{ab}$ & $1,7 \mathrm{~b}$ & $9,0 \mathrm{~b}$ & $43,4 \mathrm{~b}$ & $248,7 \mathrm{a}$ & $44,9 \mathrm{~b}$ & $293,6 \mathrm{~b}$ \\
\hline Sulfometuron & $3,5 \mathrm{a}$ & $5,8 \mathrm{~b}$ & $6,2 \mathrm{a}$ & $12,0 \mathrm{a}$ & $57,7 \mathrm{a}$ & $199,3 \mathrm{~b}$ & $63,3 \mathrm{~b}$ & $262,6 \mathrm{c}$ \\
\hline
\end{tabular}

${ }^{1 /}$ Dados transformados em $\sqrt{x \square 1}$ para análise, mas são apresentados os dados originais. ${ }^{2 /}$ Médias seguidas pela mesma letra, na coluna, não diferem entre si pelo teste de Duncan $(\mathrm{p}<0,05)$. 
maior sensibilidade a nicosulfuron e sulfometuron-methyl que 'Atlantic'.

\section{LITERATURA CITADA}

ANDRES, A.; FLECK, N. G. Efeitos de imidazolinona e sulfoniluréias sobre a produção de sementes e emergência de plântulas de quinquilho. Planta Daninha, v. 12, p. 63-69, 1994.

DEXTER, A. G.; GUNSOLUS, J. L.; CURRAN, W. S. Herbicide mode of action and sugarbeet injury symptoms. Fargo: North Dakota State University/ North Dakota State Extension Service, 1994. 21 p.

EBERLEIN, C. V.; GUTTIERI, M. J. Potato (Solanum tuberosum) response to simulated drift of imidazolinone herbicides. Weed Sci., v. 42, p. 70-75, 1994.

FLECK, N. G.; VIDAL, R. A. Injúria potencial de herbicidas de solo ao girassol. II-Chlorimuron-ethyl. Planta Daninha, v. 11, p. 44-48, 1993.

ISAACS, M. A. et al. Effects of late-season herbicide applications on sicklepod (Cassia obtusifolia) seed production and viability. Weed Sci., v. 37, p. 761-765, 1989.

MIRANDA FILHO, H. S. Batata. In: RAIJ, B. van et al. (Eds.). Recomendações de adubação e calagem para o Estado de São Paulo. 2.ed. Campinas: Instituto Agronômico \& Fundação IAC, 1996. p. 225.
MIRANDA FILHO, H. S.; GRANJA, N. P.; MELO, P. C. T. Cultura da batata. 2003. 68 p. (Apostila).

OLIVEIRA Jr., R. S. Mecanismos de ação de herbicidas. In: OLIVEIRA Jr., R. S. ; CONSTANTIN, J. Plantas daninhas e seu manejo. Guaíba: Agropecuária, 2001. p. 207-260.

RODRIGUES, B. N.; ALMEIDA, F. S. Guia de herbicidas. 5.ed. Londrina: edição dos autores, 2005. 592 p.

RUEDELL, J.; THEISEN, G.; BIANCHI, M. A. Herbicidas e tecnologia de aplicação. In: THEISEN, G.; RUEDEL, J. Tecnologia de aplicação de herbicidas - teoria e prática. Cruz Alta: Aldeia Norte, 2004. p. 9-11.

THORNTON, R. E.; EBERLEIN, C. V. Chemical injury. In: STEVENSON, W. R. et al. Compendium of potato diseases. 2.ed. 2001. Saint Paul: American Phytopathological Society, 2001. p. 92-94.

TREZZI, M. M.; VIDAL, R. A. Herbicidas inibidores da ALS. In: VIDAL, R. A.; MEROTO Jr., A. (Eds.).

Herbicidologia. Porto Alegre: Edição dos Autores, 2001. p. 25-36.

TURKENSTEEN, L. J.; MULDER, A. Herbicide injury: remaining non-parasitic deffects. In: DELLEMAN, J. et al. Potato diseases; diseases, pests and deffects. Dean Haag: Cardapeel Wereld/NIVAP, 2005. p. 242-244.

VENCILL, W. K. (Ed.). Herbicide handbook. Lawrence: Weed Science Society of America, 2002. 493 p. 